\title{
Isolated subdural hematoma secondary to Dural arteriovenous fistula: a case report and literature review
}

\author{
Guichen $\mathrm{Li}^{1+}$, Yang Zhang ${ }^{2 \dagger}$, Jinchuan Zhao ${ }^{2}$, Xiaobo Zhu ${ }^{2}$, Jinlu Yu ${ }^{2^{*}}$ and Kun $\mathrm{Hou}^{2^{*}}$ (D)
}

\begin{abstract}
Background: Dural arteriovenous fistula (DAVF) is an uncommon subtype among the intracranial arteriovenous malformations, which is characterized by pathological anastomoses between meningeal arteries and dural venous sinuses, meningeal veins, or cortical veins. While intracerebral hemorrhage accounts for most of the hemorrhagic cases in patients with DAVF, isolated subdural hematoma (SDH) is rarely reported.

Case presentation: A 45-year-old man was admitted for a progressively worsening headache over 2 weeks. Head computed tomography on admission revealed an isodense chronic SDH (CSDH) on the left hemisphere with mild midline shift. Further angiography of the external carotid artery revealed a DAVF at the transverse sinus. The DAVF was embolized via the middle meningeal artery. His CSDH gradually resolved without surgical intervention. In order to further elucidate this rare entity, a review of relevant literature was also conducted.

Conclusions: Isolated SDH is a rare complication of DAVF. In this report, we presented a rare case of CSDH secondary to an intracranial DAVF. According to this case report and our literature review, the so-called benign type of DAVF without cortical venous drainage does not always warrant a benign process and might be complicated with $\mathrm{SDH}$. Careful preoperative investigation is needed for relative young patients presenting with idiopathic or atypical SDH.
\end{abstract}

Keywords: Dural arteriovenous fistula, Subdural hematoma, Cortical venous drainage, Middle meningeal artery

\section{Background}

Dural arteriovenous fistula (DAVF) is an uncommon subtype among the intracranial arteriovenous malformations (AVMs), which is characterized by pathological anastomoses between meningeal arteries and dural venous sinuses, meningeal veins, or cortical veins [1]. From a recent epidemiologic survey of DAVF in Japan, the initial clinical presentation was intracranial hemorrhage in $16 \%$ of the inflicted patients [2]. While intracerebral hemorrhage (ICH) accounts for most of the hemorrhagic cases, isolated subdural hematoma $(\mathrm{SDH})$ is rarely reported $[3,4]$. In the current study, we

\footnotetext{
* Correspondence: jlyu@jlu.edu.cn; houkunscience@163.com; houkunsciene@163.com

Guichen Li and Yang Zhang contribute equally to this manuscript and they are co-first authors.

${ }^{2}$ Department of Neurosurgery, The First Hospital of Jilin University, 71 Xinmin Avenue, Changchun, Jilin 130021, China

Full list of author information is available at the end of the article
}

report a rare case of DAVF presenting with isolated chronic subdural hematoma (CSDH). Furthermore, a review of the literature was also conducted to further illustrate the clinical profiles of this rare entity.

\section{Case presentation}

A 45-year-old man was admitted for a progressively worsening headache over 2 weeks. He denied history of recent head trauma or anticoagulation and antiplatelet medication. General and neurologic examinations were not remarkable on admission. Routine laboratory investigations including coagulation profiles and platelet function were within normal limits. Head computed tomography $(\mathrm{CT})$ on admission revealed an isodense $\mathrm{CSDH}$ on the right hemisphere with mild midline shift (Fig. 1a). A CT angiography (CTA) was performed to rule out any intracranial vascular malformation. A DAVF was noticed at the transverse sinus with dilated cortical venous drainage (Fig. 1b). So, a digital subtraction

(c) The Author(s). 2019 Open Access This article is distributed under the terms of the Creative Commons Attribution 4.0 International License (http://creativecommons.org/licenses/by/4.0/), which permits unrestricted use, distribution, and 

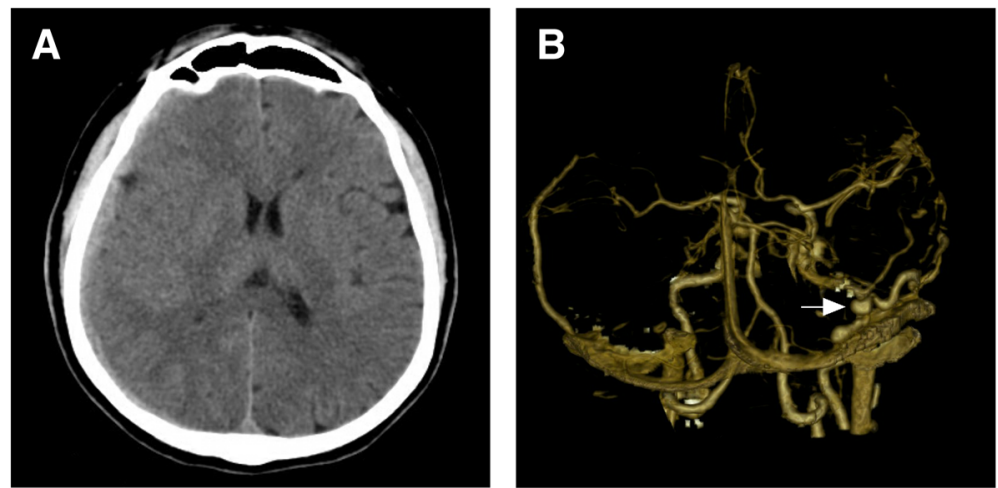

Fig. 1 (a) Head CT shows an isodense CSDH on the right hemisphere with mild midline shift. (b) CTA reveals a DAVF located at the transverse sinus with dilated cortical venous drainage (arrow). CT: computed tomography; CSDH: chronic subdural hematoma; CTA: CT angiography; DAVF: dural arteriovenous fistula

angiography (DSA) of the external carotid artery and DAVF embolization was planned.

No anomaly was noticed during selective angiography of the internal carotid and vertebral arteries and the left external carotid artery. Selective angiography of the right external carotid artery showed that the DAVF was located at the transverse sinus and fed by posterior branch of the middle meningeal artery (MMA), the occipital artery, and the posterior meningeal artery and drained to the occipital cortical veins with venous ectasia (Fig. 2a-b). The DAVF was classified as type IV according to the Cognard classification. The embolization was performed via the MMA. The Headway duo catheter was used and accessed to the DAVF, and Onyx was injected until the shunt disappeared (Fig. 2c-d). The patient experienced an uneventful recovery. His CSDH gradually resolved in 1 month (Fig. 3). No neurologic deficit was noticed.

\section{Literature review}

A PubMed search of published studies written in English and Chinese was conducted on June 30th, 2017. The following key words were used in relevant combinations: dural arteriovenous fistula, dural arteriovenous malformation, subdural hematoma, subdural haematoma, subdural hemorrhage, and subdural haemorrhage. The reference lists of the identified articles were also manually searched for additional studies. Studies of which full text could not be obtained or those without sufficient individualized description of the isolated SDH cases mixed in larger case series were excluded.

Finally, 13 articles containing 14 patients were identified [3-15]. In all 15 patients ( 9 females, 60\%) including 1 case in our institution were included for the final interpretation (Table 1). The inflicted patients were aged from 27 to 82 years $(55.5 \pm 8.6)$.Of note, $12(80 \%)$ of the 15 patients were aged between 40 and 60 years of age, and $8(53.3 \%)$ patients were between 50 and 60 years. Sides of the DAVF or SDH were obtained in 13 patients with $9(69.2 \%)$ located at the left side and 4 at the right side. The intracranial locations of DAVF were anterior fossa (2), middle fossa (2), frontal region (2), parietal region (3), temporal region (2), and occipital region (2). The types of SDH were CSDH (7/15), acute SDH (ASDH) (7/15), and undefined SDH (1/15). Of the 12 patients feeding artery could be identified, MMA was the commonest feeding artery (8/12, 66.7\%). Multiple feeding arteries were identified in $3(25 \%)$ patients. The causes of DAVF were only defined in 3 patients (2 iatrogenic and 1 traumatic), with the rest undefined or not mentioned. Cognard classifications (Table 2) of the DAVF were reported or deduced from the reports in 12 patients, with type I, type III, and type IV in 7, 2, and 3 patients respectively. The treatment strategies included hematoma evacuation (2/15), CSDH drainage and DAVF embolization (5/15), craniotomy and DAVF resection (3/15), DAVF embolization and hematoma evacuation (1/15), DAVF embolization (2/15), and not applicable or not mentioned (2/15). Of the 12 patients with direct description of outcome, 7 (58.3\%) patients were neurological intact, 3 (25\%) patients with neurological deficits, and $2(16.7 \%)$ died.

\section{Discussion}

DAVF is an uncommon subtype of intracranial AVMs [1]. In a Scottish population-based study in adults, the detection rate of DAVF was 0.16 per 100,000 adults per year, whereas the rate of all intracranial vascular malformations was 2.27 per 100,000 adults per year in the same population [16]. The manifestations of DAVF are diverse. In the recent Japanese survey by Kuwayama $\mathrm{N}$ et al., the initial clinical presentation was ocular symptoms, tinnitus, intracranial hemorrhage, and non-hemorrhagic neurological deficits in $45,20,16$, and 

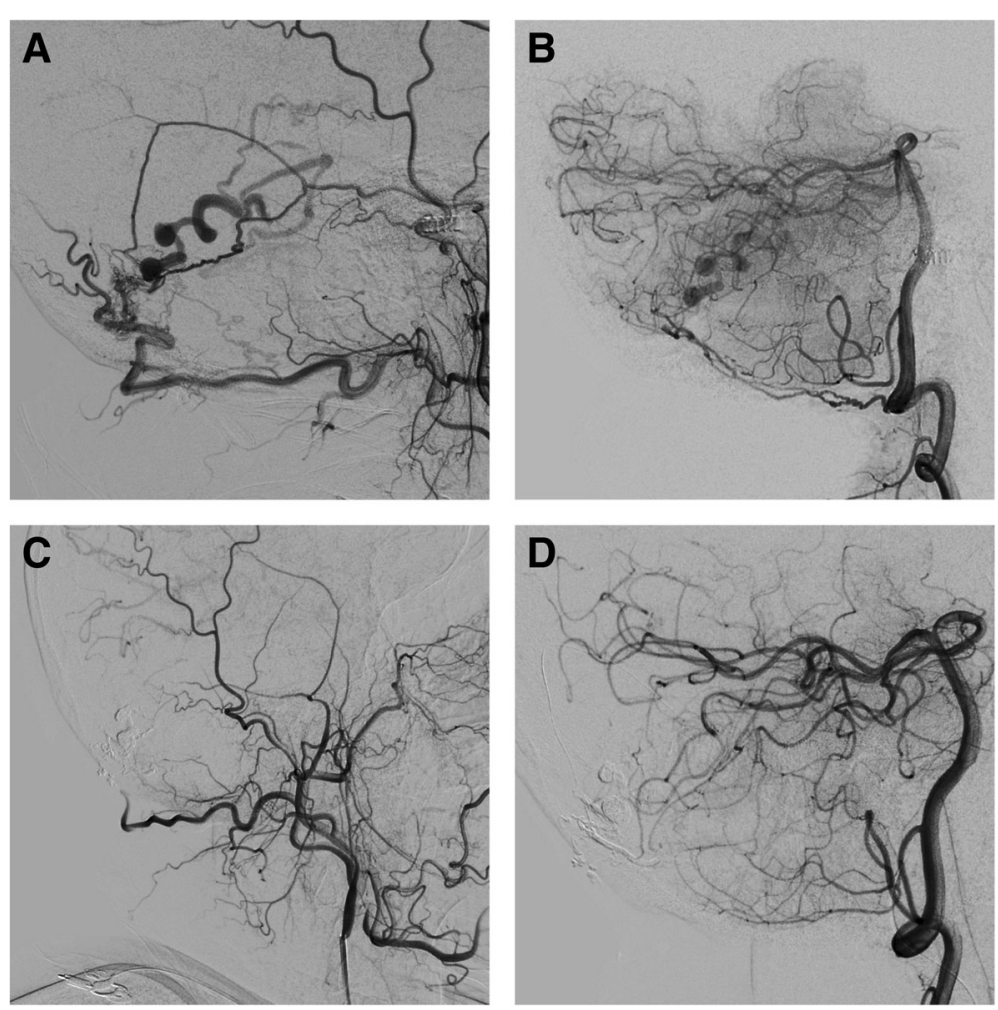

Fig. 2 (a) Preoperative DSA of the right external carotid artery shows that the DAVF is fed by the branch of MMA and OA, and drains to the dilated occipital cortical vein. (b) DSA of the right vertebral artery shows that the DAVF also receives blood supply from the PMA. (c-d) DAVF disappears after Onyx embolization injection via the branch of MMA. DSA: digital subtraction angiography; DAVF: dural arteriovenous fistula; MMA: middle meningeal artery; OA: occipital artery; PMA: posterior meningeal artery

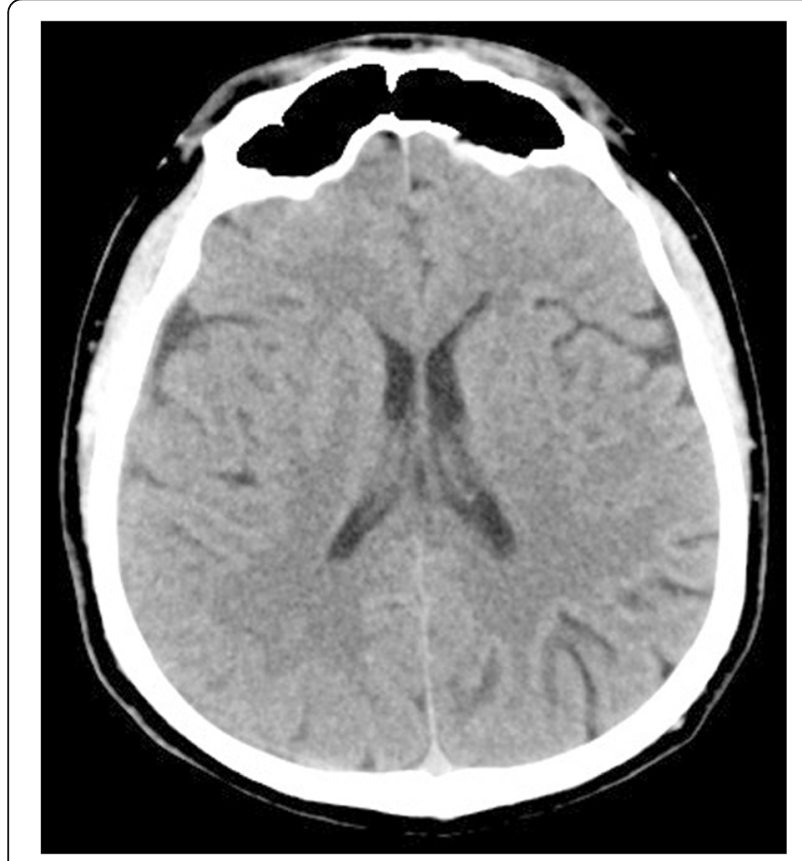

Fig. 3 Head CT shows spontaneous resolution of the CSDH. CT: computed tomography; CSDH: chronic subdural hematoma
$20 \%$ of the patients respectively [2]. In the hemorrhagic patients, isolated SDH was only reported sporadically [3-15]. According to the literature, the majority of DAVFs are acquired in an idiopathic fashion, only a small proportion results from causes as trauma, infection, and iatrogenic injury $[1,17]$. In this study, including our case, the causes of DAVF and associated SDH were only defined in 3 patients (2 iatrogenic and 1 traumatic), with the rest undefined or not mentioned.

The initial clinical presentation is not specific in patients with DAVF associated SDH. Just as presented in our case, headache (chronic, acute, or progressive) was the most common complaint. As a result of its rarity in occurrence, hardly could we ever associate DAVF with an SDH. In case of a patient presenting with SDH, there is no specific indication in imaging and clinical presentation that could imply the possibility of an underlying DAVF. However, there are some points that might indicate the existence of some underlying disorders: a) relatively young age, b) no evident history of head trauma, c) no coagulopathy or anticoagulation and antiplatelet medication, d) spontaneous occurrence of $\mathrm{SDH}$, e) recurrent or refractory SDH that recurs in a short period after previous satisfactory hematoma evacuation. 





Table 2 Cognard classification of intracranial DAVF

\begin{tabular}{|c|c|}
\hline Type & Venous drainage \\
\hline Type I & Anterograde drainage into venous sinus \\
\hline \multicolumn{2}{|l|}{ Type ॥ } \\
\hline$\| \mathrm{A}$ & Venous drainage into dural sinus with retrograde flow \\
\hline$\| \mathrm{B}$ & $\begin{array}{l}\text { Venous drainage into dural sinus with normal } \\
\text { antegrade flow and CVD }\end{array}$ \\
\hline$\| A+B$ & $\begin{array}{l}\text { Venous drainage into dural sinus with retrograde } \\
\text { flow and CVD }\end{array}$ \\
\hline Type III & Venous drainage directly into subarachnoid vein (CVD only) \\
\hline Type IV & $\begin{array}{l}\text { Venous drainage directly into subarachnoid vein with } \\
\text { venous ectasia }\end{array}$ \\
\hline Type V & Venous drainage directly into spinal perimedullar veins \\
\hline
\end{tabular}

The natural history of DAVF is primarily determined by the pattern of venous drainage $[1,17,18]$. Patients with cortical venous drainage (CVD) (especially with venous ectasia) have an aggressive natural history including $\mathrm{ICH}$ and nonhemorrhagic neurologic deficits (NHNDs). While DAVF without CVD manifests a benign process and rarely causes ICH or NHNDs. In this literature review, Cognard classification (Table 2) of the DAVF were reported or deduced from the reports in 12 patients, with type I, type III, and type IV in 7, 2, and 3 patients, respectively. Seven (58.3\%) of the 12 patients harbored the supposed benign type I DAVF, which is somewhat inconsistent with the classical viewpoint $[1$, 17]. Hence, DAVF with CVD demonstrates an aggressive natural history and might be complicated with any kind of intracranial hemorrhage including SDH. The so-called benign type of DAVF without CVD does not always warrant a benign process and could also be complicated with SDH.

There was no consensus on the treatment of DAVF and its associated SDH. The treatment strategies depend on specific circumstances. In the case of massive ASDH, hematoma evacuation combined with simultaneous DAVF resection was the preferred strategy [7, 8, 13]. While burr-hole drainage combined with DAVF embolization was more suitable for CSDH patients $[4,6$, $7,12]$. When the SDH did not cause evident intracranial hypertension or neurological deficit, mere DAVF embolization could also be selected [4, 14, 15]. Because the mass effect of CSDH in our patient was mild, we just embolized the DAVF at primary treatment. And the CSDH resolved spontaneously.

\section{Limitations}

This is an isolated case report and a review of the literature. The data we interpreted were extracted from sporadic cases. As a result of the nature of this study, statistical analysis could not be conducted. Hence, the conclusion we achieved in the text is just a narrative interpretation of the past studies and future studies with larger case series are anticipated.

\section{Conclusion}

DAVF is an uncommon subtype of intracranial AVMs. Isolated $\mathrm{SDH}$ including $\mathrm{ASDH}$ and $\mathrm{CSDH}$ is a rare complication of DAVF. The so-called benign type of DAVF without CVD does not always warrant a benign process and could also be complicated with $\mathrm{SDH}$. Careful preoperative investigation is needed for relative young patients presenting with idiopathic or atypical SDH.

\section{Abbreviations}

ASDH: Acute subdural hematoma; AVMs: Arteriovenous malformations; CSDH: Chronic subdural hematoma; CT: Computed tomography; CTA: CT angiography; CVD: Cortical venous drainage; DAVF: Dural arteriovenous fistula; DSA: Digital subtraction angiography; ICH: Intracerebral hemorrhage; MMA: Middle meningeal artery; NHNDs: Nonhemorrhagic neurologic deficits; SDH: Subdural hematoma

\section{Acknowledgements}

None.

\section{Funding}

None.

\section{Availability of data and materials}

The datasets used and analysed during the current study are available from the corresponding author on reasonable request.

\section{Authors' contributions}

Conception and design: GL,XZ, YZ. Acquisition of data: JZ, JL. Analysis andinterpretation of data: KH, GL. Drafting the article: GL, KH. Critically revising the article: $\mathrm{J}, \mathrm{KH}$. All of the authors have read and approved the final manuscript.

\section{Ethics approval and consent to participate}

This study was approved by the institutional review board of The First Hospital of Jilin University and informed written consent was obtained from the patient.

\section{Consent for publication}

Written informed consent was obtained from the patient for publication of this manuscript and any accompanying images. Copy of the written consent is available for review by the editor of this journal.

\section{Competing interests}

The authors declare that they have no competing interests.

\section{Publisher's Note}

Springer Nature remains neutral with regard to jurisdictional claims in published maps and institutional affiliations.

\section{Author details}

'Department of Neurology, The First Hospital of Jilin University, Changchun, Jilin, China. ${ }^{2}$ Department of Neurosurgery, The First Hospital of Jilin University, 71 Xinmin Avenue, Changchun, Jilin 130021, China. 
Received: 16 November 2017 Accepted: 12 March 2019

Published online: 21 March 2019

\section{References}

1. Reynolds MR, Lanzino G, Zipfel GJ. Intracranial Dural Arteriovenous Fistulae. Stroke. 2017:48(5):1424-31.

2. Kuwayama N. Epidemiologic survey of Dural arteriovenous fistulas in Japan: clinical frequency and present status of treatment. Acta Neurochir Suppl. 2016;123:185-8

3. Maiuri F, laconetta G, Sardo L, Briganti F. Dural arteriovenous malformationassociated with recurrent subdural haematoma and intracranial hypertension. Br J Neurosurg. 2001;15(3):273-6.

4. Kim E. Refractory spontaneous chronic subdural hematoma: a rare presentation of an intracranial arteriovenous fistula. J Cerebrovasc Endovasc Neurosurg. 2016;18(4):373-8.

5. Ito J, Imamura H, Kobayashi K, Tsuchida T, Sato S. Dural arteriovenous malformations of the base of the anterior cranial fossa. Neuroradiology. 1983;24(3):149-54.

6. Halbach W, Higashida RT, Hieshima GB, Rosenblum M, Cahan L. Treatment ofdural arteriovenous malformations involving the superior sagittal sinus. AJNR Am J Neuroradiol. 1988;9(2):337-43.

7. Pappas $C T$, Zabramski JM, Shetter AG. latrogenic arteriovenous fistula presenting as a recurrent subdural hematoma. Case report. J Neurosurg. 1992;76(1):134-6.

8. Başkaya MK, Suzuki Y, Seki Y, Negoro M, Ahmed M, Sugita K. Dura arteriovenous malformations in the anterior cranial fossa. Acta Neurochir. 1994;129(3-4):146-51.

9. Komiyama M, Yasui T, Tamura K, Nagata Y, Fu Y, Yagura H. Chronic subdural hematoma associated with middle meningeal arteriovenous fistula treated by a combination of embolization and burr hole drainage. Surg Neurol. 1994:42(4):316-9.

10. Duffau $H$, Lopes $M$, Janosevic $V$, et al. Early rebleeding from intracranial duralarteriovenous fistulas: report of 20 cases and review of the literature. J Neurosurg. 1999;90(1):78-84.

11. Kominato Y, Matsui K, Hata Y, et al. Acute subdural hematoma due to arteriovenous malformation primarily in dura mater: a case report. Leg Med (Tokyo). 2004;6(4):256-60.

12. Kohyama S, Ishihara S, Yamane F, Kanazawa R, Ishihara H. Dural arteriovenous fistula presenting as an acute subdural hemorrhage that subsequently progressed to a chronic subdural hemorrhage: case report. Minim Invasive Neurosurg. 2009;52(1):36-8.

13. Ogawa K, Oishi M, Mizutani T, Maejima S, Mori T. Dural arteriovenous fistula on the convexity presenting with pure acute subdural hematoma. Acta Neurol Belg. 2010;110(2):190-2.

14. de Aguiar GB, Veiga JC, Silva JM, Conti ML. Spontaneous acute subdural hematoma: a rare presentation of a dural intracranial fistula. J Clin Neurosci. 2016;25:159-60.

15. Mewada T, Ohshima T, Yamamoto T, Goto S, Kato Y. Usefulness of embolization for iatrogenic Dural arteriovenous fistula associated with recurrent chronic subdural hematoma: a case report and literature review. World Neurosurg. 2016;92:584.e7-584 e10.

16. Al-Shahi R, Bhattacharya JJ, Currie DG, et al. Scottish intracranial vascular malformation study collaborators. Prospective, population-based detection of intracranial vascular malformations in adults: the Scottish intracranial vascular malformation study (SIVMS). Stroke. 2003;34(5):1163-9.

17. Elhammady MS, Ambekar S, Heros RC. Epidemiology, clinical presentation, diagnostic evaluation, and prognosis of cerebral dural arteriovenous fistulas. Handb Clin Neurol. 2017;143:99-105.

18. Zipfel GJ, Shah MN, Refai D, Dacey RG Jr, Derdeyn CP. Cranial duralarteriovenous fistulas: modification of angiographic classification scales based on new natural history data. Neurosurg Focus. 2009;26(5):E14.

\section{Ready to submit your research? Choose BMC and benefit from:}

- fast, convenient online submission

- thorough peer review by experienced researchers in your field

- rapid publication on acceptance

- support for research data, including large and complex data types

- gold Open Access which fosters wider collaboration and increased citations

- maximum visibility for your research: over $100 \mathrm{M}$ website views per year

At BMC, research is always in progress.

Learn more biomedcentral.com/submissions 